DOT/FAA/AM-01/11

Office of Aerospace Medicine

Washington, DC 20591

\section{Assessment of Head-Injured Aircrew: Comparison of FAA and USAF Procedures}

Edna Fiedler

Daniel R. Orme

William Mills

Civil Aerospace Medical Institute

Federal Aviation Administration

Oklahoma City, Oklahoma 73125

John C. Patterson

School of Aerospace Medicine

2507 Kennedy Circle

Brooks Air Force Base, Texas 78235

July 2001

Final Report

This document is available to the public through the National Technical Information Service, Springfield, Virginia 22161.

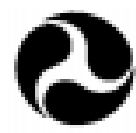

U.S. Department of Transportation

Federal Aviation Administration 


\section{$\mathrm{N} O \mathrm{~T}$ I C E}

This document is disseminated under the sponsorship of the U.S. Department of Transportation in the interest of information exchange. The United States Government assumes no liability for the contents thereof. 


\section{Technical Report Documentation Page}

\begin{tabular}{|c|c|c|c|c|}
\hline $\begin{array}{l}\text { 1. Report No. } \\
\text { DOT/FAA/AM-01/11 }\end{array}$ & \multicolumn{2}{|c|}{ 2. Government Accession No. } & \multicolumn{2}{|c|}{ 3. Recipient's Catalog No. } \\
\hline \multicolumn{3}{|c|}{$\begin{array}{l}\text { 4. Title and Subtitle } \\
\text { Assessment of Head-Injured Aircrew: Comparison of FAA and USAF } \\
\text { Procedures }\end{array}$} & \multicolumn{2}{|l|}{$\begin{array}{l}\text { 5. Report Date } \\
\text { July } 2001\end{array}$} \\
\hline \multicolumn{3}{|c|}{$\begin{array}{l}\text { 7. Author(s) } \\
\text { Fiedler, E.R., Orme, D.R., Mills, W. }{ }^{1} \text {, and Patterson, J.C. }\end{array}$} & \multicolumn{2}{|c|}{ 8. Performing Organization Report No. } \\
\hline $\begin{array}{l}\text { 9. Performing Organization Name and Address } \\
{ }^{1} \text { FAA Civil Aerospace Medical Institute } \\
\text { P.O. Box } 25082 \\
\text { Oklahoma City, OK } 73125\end{array}$ & \multicolumn{2}{|c|}{\begin{tabular}{|l}
${ }^{2}$ School of Aerospace Medicine \\
2507 Kennedy Circle \\
Brooks Air Force Base, TX 78235
\end{tabular}} & \multicolumn{2}{|c|}{ 10. Work Unit No. (TRAIS) } \\
\hline \multicolumn{3}{|l|}{$\begin{array}{l}\text { 12. Sponsoring Agency name and Address } \\
\text { Office of Aerospace Medicine } \\
\text { Federal Aviation Administration } \\
800 \text { Independence Ave., S.W. } \\
\text { Washington, DC } 20591\end{array}$} & \multicolumn{2}{|c|}{ 13. Type of Report and Period Covered } \\
\hline \multicolumn{5}{|c|}{ 15. Supplemental Notes } \\
\hline \multicolumn{5}{|c|}{$\begin{array}{l}\text { 16. Abstract } \\
\text { The Federal Aviation Administration and the United } \\
\text { whether aviators who have sustained head injuries are } \\
\text { this paper is to first explain the major differences in } \\
\text { outline these procedures and rules, note their similari } \\
\text { weaknesses of each approach, and discuss the possible } \\
\text { material are presented to illustrate both evaluation me }\end{array}$} \\
\hline \multicolumn{2}{|c|}{$\begin{array}{l}\text { 17. Key Words } \\
\text { Aviators, Pilots, Traumatic Head Injury, CogScreen }\end{array}$} & \multicolumn{3}{|c|}{$\begin{array}{l}\text { 18. Distribution Statement } \\
\text { Document is available to the public through } \\
\text { the National Technical Information Service, } \\
\text { Springfield, VA } 22161\end{array}$} \\
\hline $\begin{array}{l}\text { 19. Security Classif. (of this report) } \\
\text { Unclassified }\end{array}$ & $\begin{array}{r}\text { 0. Security Classif. (of } \\
\text { Un }\end{array}$ & & $\begin{array}{c}\text { 1. No. of Pages } \\
10\end{array}$ & 22. Price \\
\hline
\end{tabular}

Form DOT F 1700.7 (8-72) $\quad$ Reproduction of completed page authorized 



\section{Assessment of Head-Injured Aircrew: Comparison of FAA and USAF Procedures}

Traumatic brain injury (TBI) frequently results in symptoms that are of aeromedical concern. Neuropsychiatric symptoms associated with TBI are wideranging but can be broadly categorized into three major areas (4). Cognitive difficulties are evident in slowed information processing speed and efficiency, reduced concentration, and memory problems. Emotional changes typically present as either exaggerated or blunted emotional responsiveness; anxiety and depression are also commonly found in this population. Finally, because of reduced executive functioning, TBI patients may have deficient self-awareness, reduced planning skills, and difficulty with impulse control. Besides neuropsychiatric symptoms there also may be focal neurological deficits, depending upon lesion location, and an increased risk for seizures. Annegers, Grabow, Groover (1), for example, noted that $12 \%, 2 \%$, and $1 \%$ of patients with severe, moderate, and mild TBI, respectively, experienced post-traumatic epilepsy requiring anticonvulsant medication within five years of injury. Feeney and Walker (2) developed a mathematical equation that can be used to predict the probability of post-traumatic seizures taking into account several risk factors.

Consequently, when pilots sustain TBI it is important that they undergo extensive evaluations to determine whether they are capable of managing the complex cognitive and psychomotor demands of flying. The burden of oversight of these evaluations falls to the Federal Aviation Administration (FAA) for private and commercial pilots, and the United States Air Force (USAF) for USAF pilots. Thus, both organizations (FAA and USAF) are similarly charged with ensuring the aeromedical fitness of pilots who return to flying following TBI. However, the missions of the USAF and the FAA are different and therefore the evaluation procedures and rules that allow for a pilot's return to flying differ. The purpose of this paper is to first explain the major differences in missions, and then outline these procedures and rules, note their similarities and differences, address the strengths and weaknesses of each approach, and discuss the possible reconciliation of these differences. Finally, brief case material will be presented to illustrate both evaluation methods.

\section{MISSIONS AND PHILOSOPHY}

Both the FAA and USAF share the goal of safe flying. While both the FAA and USAF medical communities have the same responsibility of overseeing pilot evaluations, their missions vary significantly. USAF medical personnel conditions must consider continuous worldwide readiness and unexpected deployments, thereby including not only safety but also the military mission. It needs to be remembered that military pilots must sometimes work in "austere environments." Such environments may include long missions, substantial and frequent $\mathrm{g}$-forces, vigilance for prolonged periods of time not only to the workings of the aircraft but also possible hostile forces, and the stresses of combat and sustained periods of separation from family. Pilots, then, must be in excellent health and there is little room for compromise. Pilots who sustain moderate and severe TBI must demonstrate no residual deficits on neurological or neuropsychological examinations before being allowed to resume flying duties. From a neuropsychological perspective, any evidence of cognitive skill decline is sufficient to result in DNIF (Duties Not to Include Flying).

The FAA mission does not take into account worldwide readiness or military mission requirements. The FAA makes decisions concerning medical qualification for the duration of the medical certificate, which can vary from six months to three years. This means the aviation medical examiner who does the general examination, any neurologists who are consulted, and the FAA physician who makes the final decision, will focus on a specific time frame. Nor does the FAA have a military mission. The FAA must balance the needs and desires of the applicant against the risks to society. "The FAA recognizes that individuals should be allowed the maximum freedom of 
choice, consistent with safety in air commerce, in deciding the extent to which their exercise of airman privileges should be limited by their personal health" (FAR 67.401 (e) for private pilots). Consistent with this viewpoint, the FAA has to balance the impact of neurological conditions with whether the pilot has a first-class (airline transport pilot), second-class (other commercial), or third-class (private pilot) medical certificate.

The commercial or airline transport pilot has to consider the life or property of others. In these cases, the importance of even a small risk for an incapacitating medical event must be considered. The Federal Air Surgeon of the FAA must establish medical standards for airline transport pilots that provide the highest possible degree of safety for the public. The FAA's Aeromedical Certification Division has the option of issuing a limited second- or third-class certificate, but there is no option for issuing a limited first-class certificate. This could be "valid only for a fully qualified two-pilot crew," "valid for agricultural duties only," or etc. Although seldom used for TBI, it is frequently used in cardiac cases.

The private pilot is not performing in a job that requires providing safe transportation of the public or the public's property. Part 67.401.e allows the private pilot "to accept reasonable risks to his or her person and property that are not acceptable in the exercise of commercial or airline transport pilot privileges, and, at the same time, considers the need to protect the safety of persons and property in other aircraft and on the ground.”

\section{DEFINITIONS AND PROCEDURES}

Rules governing physical qualifications for civilian flying duties are found in Federal Aviation Regulations (FAR) Title 14 of Code of Federal Regulations (CFR) Part 67 Medical Standards and Certification (Part 67), and, for Air Force aviators, Air Force Instruction (AFI) 48-123 and Waiver Guidelines. The interested reader should consult these for definitive guidance. Much of the content of this paper is derived from these standards.

\section{Medical certificate categories}

There are three classes of medical certificates that qualify individuals for civilian flying duties: firstclass, second-class, and third-class. A first-class airman certificate is needed to receive an airline transport pilot certificate. A second-class medical certificate is required for a commercial pilot, flight engineer, flight navigator, or Air Traffic Control Specialist (ATCS), not including FAA employee ATCSs. Finally, a thirdclass medical certificate is for private, recreational, or student pilots (Part 67-11 of Title 14 of the Code of Federal Aviation Regulations; 14 CFR, amendment 67-11). Glider and Free Balloon Pilots do not require a medical certificate of any class. Neurological standards for a first-class, second-class, and third-class airman medical certificate are the same (CFR, Part 67.109).

For USAF aviators, there are also three medical classes that qualify for flying duties. They are: Flying Class I (FC-I) for entry into pilot training; Flying Class II (FC-II) for individuals who are in pilot training, rated officers, and physicians who are Flight Surgeons; and Flying Class III (FC-III) for non-rated individuals whose duties involve flying. These include, for example, boom operators, crew chiefs, and load masters.

\section{Waiver consideration}

Once medically qualified for flying, aviators sometimes acquire illnesses or injuries that render them medically disqualified. Head injuries can be disqualifying for both civilian and USAF pilots. However, there are occasions when head-injured aviators can return to flying. This requires a request for a waiver of the medical condition. For civilian aviators, factors that are considered in the waiver process include:

- any current or recent neurological symptoms or neurological or other medical findings

- the availability of an explanation for the cause of the problem that is acceptable in terms of risk for future recurrence

- any recognized factors involving the risk of future adverse neurological events or of other adverse events

- the anatomic integrity and functional status of the nervous system as determined by appropriate evaluative techniques

In the USAF, standards for consideration of waiver are remarkably similar. Overriding considerations are that the medical condition should:

- not pose a risk of sudden incapacitation

- pose minimal potential for subtle performance decrements, particularly with regard to the higher senses

- be resolved or be stable and be expected to remain so under the stresses of the aviation environment 
- if the possibility of progression or recurrence exists, the first symptoms or signs must be easily detectable and not pose a risk to the individual or the safety of others

- cannot require exotic tests, regular invasive procedures, or frequent absences to monitor for stability or progression

- must be compatible with the performance of sustained flying operations in austere environments

Head-injured fliers usually do not meet these general standards. There is concern for potential seizures and this presents a "risk of future adverse neurological events" or "risk of sudden incapacitation." Also, they may sustain a decline in cognitive skills that, for mild head injuries, may not be immediately apparent in a clinical interview or physical examination but may be evident upon neuropsychological evaluation. This represents "current neurological symptoms" and the "potential for subtle performance decrements." With experienced fliers who have very mild deficits, it could be reasoned that their duties involve overlearned skills and that their cognitive deficits are so subtle as to not interfere with their duty performance. While this may be true for routine flights, "sustained flying operations in austere environments" and aircraft emergencies present altogether different situations where cognitive abilities must function at peak levels. Consequently, even mild deficits may be incompatible with flying duties. A request for a waiver of medical condition is submitted when these general and other specific standards are met.

\section{Medical specialists}

The FAA relies heavily on aviation medical examiners (AMEs), community physicians designated by the FAA to complete medical evaluations. These physicians work out of their own offices or designated places of employment. The AME is given the authority to accept applications and perform physical examinations necessary to determine qualifications for the issuance of second- and third-class FAA airman medical certificates under and in accordance with 14CFR67 and the 1999 Guide for Aviation Medical Examiners (FAA, 1999). The senior aviation medical examiner (SME) has the additional authority to determine qualifications for the issuance of first-class FAA airman medical certificates under and in accordance with 14CFR67. Final decision-making rests with the FAA Federal Air Surgeon and his staff, not in the neurologists or neuropsychologists who do the evaluations.

Medical management of USAF aviators is the duty of flight surgeons. All flying units have flight surgeons assigned to them, and they are on flying orders that require them to average at least four hours of flying per month. Flight surgeons act as general medical officers to their assigned flying squadrons and, when their flying unit deploys, deploy with them. In this manner, they are intended to have intimate knowledge of not only aviation but also of the flying communities to which they are assigned. The oversight of waiver recommendations is always the responsibility of flight surgeons and, ultimately, the decision whether to grant a waiver is also decided by a delegated USAF Surgeon General authority. This decision is made at different levels (e.g., base, major command) depending upon the medical condition in question.

\section{Procedures}

When fliers sustain TBI they are evaluated by local AMEs or flight surgeons, for civilian and military fliers, respectively, who then manage the cases and submit waiver packages, if necessary. In the FAA system, the AME performs a physical examination, obtains a medical specialist's opinion, if necessary, and submits a narrative incorporating all of the pertinent findings to the FAA Civil Aerospace Medical Institute for disposition decisions. When it is necessary to obtain a specialist's opinion, the flier must select a provider and ensure the AME receives a summary of the findings of that evaluation. The USAF's system is more complex. In all cases, a neurological evaluation is required and, for Category 36 head injuries, must be conducted by a neurologist. While Category 1 and 2 closed head injury (CHI) evaluations are conducted by the local flight surgeon, Category 3-5 CHI examinations must be at the USAF's Aeromedical Consultation Service (ACS). Neuropsychological evaluations are also required for all but Category 1 head injuries and, with the exception of Category 2, these must be conducted at the ACS. However, the results of neuropsychological evaluations for Category $2 \mathrm{CHI}$ are still reviewed by ACS neuropsychologists and recommendations based on this review are offered. Other medical consultations, if necessary, are arranged by the flight surgeon 
who is managing the flier's waiver package or the ACS and are usually with military providers. ACS evaluation narrative summaries are added to the waiver package and submitted to the appropriate medical authority.

\section{TWO CASES}

\section{USAF case presentation}

The patient was a 34-year-old USAF fighter pilot with more than 1,500 total flying hours. Playing pitcher on a softball team, he ran for a pop-up fly and collided with another player. He struck his right temporal area against the other player's head but sustained no loss of consciousness. Both players fell to the ground, got back up, and continued to play. The patient finished the last 30 minutes of the game but, as the evening and game progressed, became increasingly confused, irritable, and incoherent. Eventually he began asking teammates, "What are we doing here?" He did not remember the collision, did not remember that his wife was in graduate school and could not recall current events. His wife took him to the local emergency room. Initially, in the ER, he could demonstrate only limited short-term memory; he knew no current events but could remember three objects five and ten minutes after their presentation. Medical examination revealed a right temporal abrasion and a normal CT scan. He was observed in the ER and he slowly regained memory for events, presidents, etc. About eight hours after the accident, he was released to go home.

He stayed home over the weekend and was evaluated by a USAF flight surgeon on Monday, two days after the accident. The pilot still could not recall anything from the time of injury until 7.5 hours later. He had no headaches, dizziness, numbness, weakness, loss of balance, or double vision and, except for some increased irritability, was otherwise asymptomatic.

Within six weeks after the injury, he was evaluated at the ACS. As a result of this evaluation he was diagnosed with moderate head injury and mild reduction in information processing speed and attention/concentration deficits. Along with other neuropsychological results (see Table 1), his IQ scores were below those commonly associated with USAF aircrew and below premorbid estimates of his ability, based on his performance on the Air Force Officer Qualification Test (AFOQT), academic, and other histories. The recommended aeromedical disposition was to disqualify him from flying duties and for him to undergo a re-evaluation in two years (in accordance with USAF aeromedical policy at the time).

In the interval (18 months) between evaluations, he did well in his job, and over the months he and his family noted a reduction in irritability. He was reevaluated at the ACS, and nearly all scores suggested improvement. Notably, his overall cognitive scores were more consistent with premorbid estimates. He was granted a waiver and returned to flying status. Had this case occurred more recently, current AF aeromedical policy would allow him to be evaluated earlier (six months from the time of injury). Given the normal CT immediately after the injury and with neuropsychological test scores showing significant improvement (e.g., corresponding with premorbid estimates), he would be recommended for return to flying (RTF) at the six-month point.

\section{Discussion of USAF case}

This is an individual who sustained a relatively mild injury (e.g., no loss of consciousness). Still, results of neuropsychological testing suggested subtle deficits in areas that are consistent with those sustained in TBI, such as reduced concentration and speed of information processing. It could be argued that the Full Scale Intelligence Quotient (FSIQ) that he obtained as a result of his initial evaluation is well within normal limits, compared to a national normative sample and, in fact, is nearly one standard deviation above the national mean. Based only on FSIQ (in practice, however, this should never be the case), the thought could be that he should have been allowed to return to flying duties. However, the mean FSIQ for USAF pilots is 120.8 with a standard deviation of only 8.2 (5); his FSIQ score, then, was lower than is typically seen in aviators. Additionally, using the patient's AFOQT score as a measure of premorbid ability (4), his premorbid FSIQ was estimated to be 121 . Altogether, it was reasonable at the time of the first evaluation to conclude that he had sustained a decline in cognitive ability. The recommendation not to return him immediately to flying duties was based on these neuropsychological data and because he presented some risk for seizure. This is a conservative approach and reflects the high level of importance placed on the safety of the individual pilot and weapons systems; it also reveals the high level of cognitive efficiency that is thought to be needed in the operational environment of the military 


\begin{tabular}{|c|c|c|c|c|c|c|c|}
\hline \multicolumn{3}{|c|}{ Wechsler Adult Intelligence Scale - Revised * } & \multicolumn{5}{|c|}{ Paced Serial Addition Test * } \\
\hline & $1^{\text {st }}$ Eval & $2^{\text {nd }}$ Eval & Series & 1 & 2 & 3 & 4 \\
\hline Verbal IQ & 106 & 127 & $1^{\text {st }}$ Eval \% Correct & 94 & 88 & 75 & 56 \\
\hline Performance IQ & 118 & 126 & $2^{\text {nd }}$ Eval \% Correct & 98 & 90 & 84 & 68 \\
\hline Full Scale IQ & 113 & 130 & \multicolumn{5}{|c|}{ Tactual Performance Test } \\
\hline \multicolumn{3}{|c|}{ Wechsler Memory Scale - Revised * } & & \multicolumn{2}{|c|}{$1^{\text {st }}$ Eval } & \multicolumn{2}{|c|}{$2^{\text {nd }}$ Eval } \\
\hline Verbal Memory & 101 & 97 & Dominant Hand ** & \multicolumn{2}{|c|}{ 4'02" } & \multicolumn{2}{|l|}{\begin{tabular}{|l}
$4^{\prime} 05^{\prime \prime}$ \\
\end{tabular}} \\
\hline Visual Memory & 94 & 108 & Nondominant Hand ** & \multicolumn{2}{|c|}{ 3'44' } & \multicolumn{2}{|l|}{ 2'51" } \\
\hline General Memory & 97 & 98 & Both Hands ** & \multicolumn{2}{|c|}{ 1'59" } & \multicolumn{2}{|l|}{ 1'48" } \\
\hline Attention/Concentration & 105 & 98 & Total Time ${ }^{\star *}$ & \multicolumn{2}{|c|}{ 9'05" } & \multicolumn{2}{|l|}{ 8'44" } \\
\hline Delayed Recall & 114 & 101 & Memory * & \multicolumn{2}{|c|}{8} & \multicolumn{2}{|l|}{9} \\
\hline \multicolumn{3}{|c|}{ Selective Remembering Test * } & Localization * & \multicolumn{2}{|c|}{1} & \multicolumn{2}{|l|}{7} \\
\hline Total Words Recalled & 99 & 127 & & & & & \\
\hline \multicolumn{8}{|c|}{ * higher scores reflect better performance } \\
\hline
\end{tabular}

aviator. Additionally, it is important to note that at reevaluation, he evidenced improvement in nearly all areas assessed. Spontaneous remission of symptoms over a period of months is to be expected with patients who have sustained CHI. It is also noteworthy that, while he was initially grounded, this pilot was later determined to be medically fit to return to flying

\section{FAA case presentation}

This is a 29 year-old airline transport pilot who had 1,700 hours of flight time when he was involved in an automobile accident (AA) as a passenger. He was ejected through the driver's side window, which he broke with his head. He was unconscious for about five minutes, after which he awakened in a confused and disoriented state. Neurological exam at the ER showed improving mental status, some memory loss, mild facial asymmetry with grimace, and bilateral Babinski signs. CT and later MRI brain scans revealed multiple cerebral contusions. He had little retrograde amnesia, but had 12 hours of post-traumatic amnesia. Examination 20 days later revealed continued word finding difficulty, poor memory, and slurred speech. About one month post-injury, he became lost in a local area. A cognitive assessment at that time involving only a few basic tests revealed grave difficulties with abstraction and memory. At two months post-AA, the pilot described a feeling of being "disconnected" and some memory difficulty. Formal neuropsychological testing $31 / 2$ months postAA showed improvement, with relatively mild defects in complex attention, psychomotor functioning, and word retrieval. (See Table 2). At eight months, comprehensive neuropsychological testing, including CogScreen, revealed continued improvement with a performance IQ of 112, compared with the previous score of 95 . However some evidence of the previously mentioned deficiencies remained. The pilot entered an intensive cognitive retraining program, and the testing was repeated 12-months post-AA with good resolution of these deficits. There was mild slowing of responses on the Grooved Pegboard Test, but values were within normal limits. Neurological exam was normal. Repeated EEGs had all been normal. Fourteen months after his head injury this pilot was again granted a first-class medical certificate and began retraining.

\section{Discussion of FAA case}

Traumatic brain injury (TBI) is one of the most challenging aeromedical certification issues because of the potential for subtle as well as sudden incapacitation and the highly variable timing and degree of eventual recovery. The FAA has internal guidelines (periodically revised) regarding certification after TBI, but each case is always evaluated individually on its own merits. This case of a commercial pilot with moderate-to-severe diffuse (multifocal) TBI, without focal neurological deficits or seizures, is fairly typical. Formal psychometric testing was required over about a one-year recovery period, there were multiple FAA physician reviews, and prior to recertification, an 


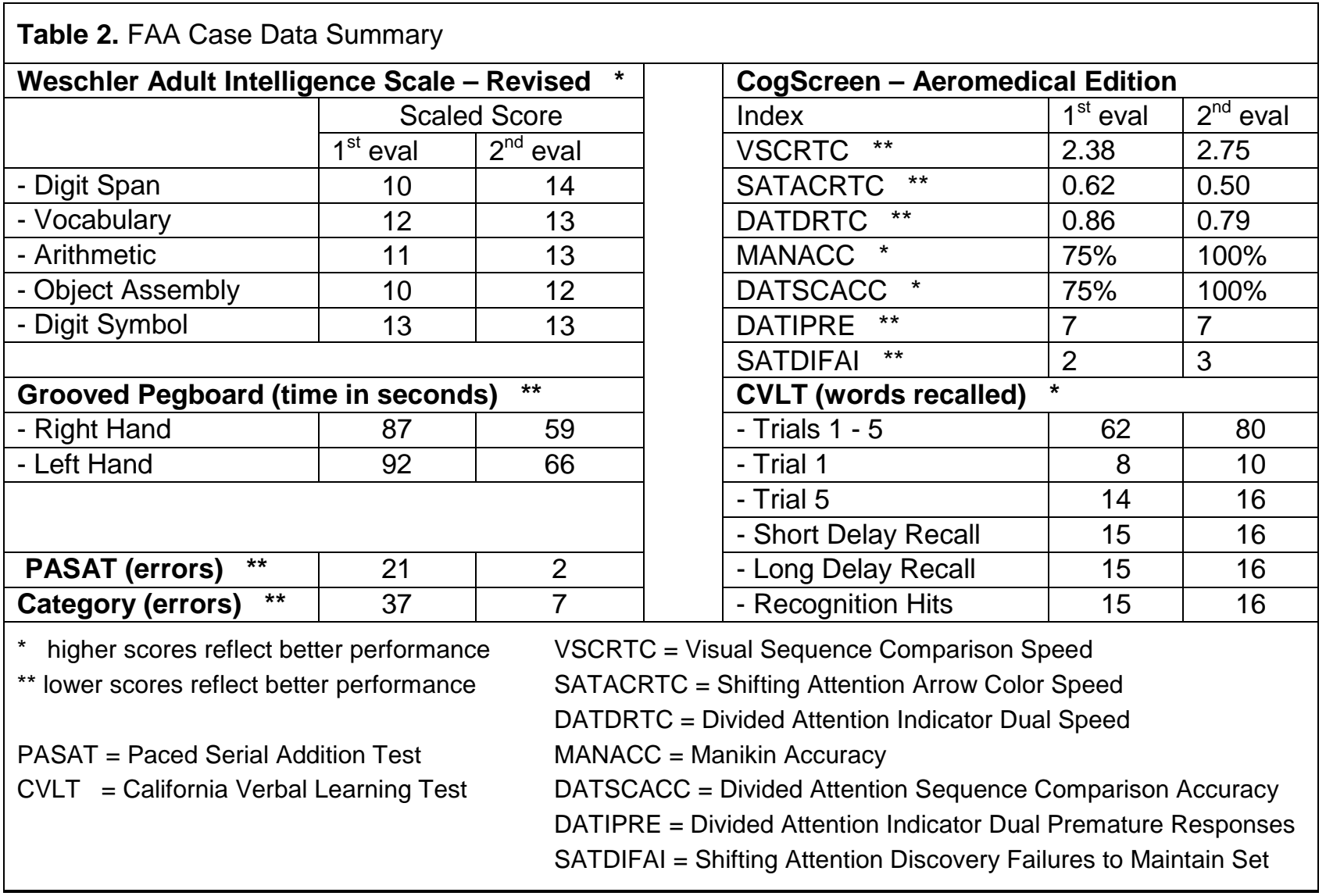

FAA-appointed neurology consultant evaluated the entire record. The pilot also retained a private aviation medical advocate to assist with his case.

For severe TBI, FAA guidelines recommend applicants should have at least a one-year recovery period and the condition considered stable by the attending physician. Applicants must provide all hospital/medical records, a complete neurologic evaluation, and, in most cases, a neuropsychological evaluation. A single posttraumatic seizure within 24 hours usually requires a one-year recovery period before consideration for medical certification. A single seizure beyond 24 hours requires four years, and two or more seizures beyond 24 hours might require ten years of being seizure-free and off medication. Certification is based on negative neurologic and neuropsychological evaluations and a normal EEG at the end of appropriate recovery period. Review by a FAA consultant may be required.

In all conditions, follow-up should be accomplished as recommended by the airman's treating physician, as recommended by a FAA-selected reviewing consultant, or as deemed appropriate based on sound medical judgment. CT scans, MRIs, cerebral angiograms, and/or EEG's may be required as part of a complete neurologic evaluation in selected cases.

\section{SUMMARY AND CONCLUSIONS}

The FAA and USAF are both tasked with oversight of aviation safety, while the USAF has the additional responsibility of balancing safety with the necessity of mission completion. While their approaches to the evaluation of head-injured aviators are quite similar, there do appear to be two overriding differences. These relate to the amount of control maintained over the evaluation process and the relative emphasis placed on the autonomy of the individual aviator. Most evaluations of head-injured USAF aircrew are conducted by USAF medical specialists who are selected by the USAF for the aviator. Except for the AME who manages individual FAA cases, civilian aviators select their own medical specialists. The USAF, then, maintains greater control over the evaluation process. The FAA, on the other hand, allows 
greater autonomy to the individual aviator. This is reflected not only in the manner in which specialists are selected for their evaluations but also in the length of time required before returning to flying after a head-injury. Assuming there are no complications, the USAF requires a five-year wait following a severe closed head injury, for example, while the FAA requires one year with no complications prior to returning to flying duties.

The cases presented highlight an important point concerning the evaluation of aviators. Aviators are, in general, a very high-functioning population. Consequently, a "normal" performance on neuropsychological tests (compared to national standardization samples) may represent a decline from premorbid abilities and warrant further investigation. In both cases presented in this paper, the results of the initial evaluations were, generally speaking, in the "average" range. However, subsequent evaluations revealed an improvement in functioning that was disproportionate to that expected by practice effect alone. This suggests that an "average" performance most likely represented a decline for these individuals. A psychologist unfamiliar with characteristic aircrew performance might have concluded after the first evaluations that there was no impairment or decline in ability and recommended a return to flying.

It is also important to remember that reduced functioning as a result of a head injury is selective and that the skills most affected are often ones that are critical to competent airmanship such as the rapid processing of information and working memory. A summary score, one that incorporates the results of several subtests (e.g., FSIQ) may mask these deficits since it consists of scores obtained on different tasks, some of which are resistant, and others that are sensitive, to cortical insult.

Should the FAA and USAF merge their procedures? Interestingly, there has already been movement in the world community towards unifying aeromedical standards. A working group involving representatives of several countries has developed a proposed standard for the evaluation of head injured aircrew that would be used by the militaries of these countries. This proposal defines various degrees of head injury and the methods of evaluation required for a waiver to return to flying. Given this, it could well be that the FAA and USAF could also develop unifying standards. Whether this would be to the advantage of both organizations and their respective taskings, however, is unclear.

There is movement toward using computer-based testing, like CogScreen, that is validated for airmen. In the future, airman-validated testing may eventually allow for a much more efficient evaluation of head-injured pilots and serve as one vehicle for unifying the FAA and USAF approaches. Current neuropsychological testing is extremely complex and expensive and could be improved by specific adaptations for defining aviation related abilities.

\section{REFERENCES}

1. Annegers J, Hauser WA, Coan SP, and Rocca WA. A population-based study of seizures after traumatic brain injuries. N Engl J Med 1998;338:20-4.

2. Feeney DM, and Walker EA. The prediction of posttraumatic epilepsy. Arch Neurol 1979;36:8-12.

3. Lezak M. Neuropsychological assessment. $3^{\text {rd }}$ ed. New York: Oxford University Press; 1995.

4. Orme,DR, Ree MJ, and Rioux P. Premorbid IQ estimates from a multiple aptitude test battery: Regression vs. equating. Archives of Clinical Neuropsychology (in press).

5. Orme DR, and Thompson WT. Multidimensional Aptitude Battery normative data using USAF pilot training candidates (manuscript submitted for publication). 
